\title{
Planejamento para a Conservação em um Clima em Mudança
}

\author{
Raquel Amaral Garcia ${ }^{1,2,3, *}$ \& Miguel Bastos Araújo ${ }^{1,2}$
}

\author{
${ }^{1}$ Departmento de Biodiversidade e Biologia Evolutiva, Museu Nacional de Ciências Naturais, \\ Conselho Superior de Investigações Cientificas - CSIC, Calle José Gutiérrez Abascal, 28006, Madrid, Espanha \\ ${ }^{2}$ Cátedra Rui Nabeiro de Biodiversidade, Universidade de Évora, \\ Centro de Investigação em Biodiversidade e Recursos Genéticos - CIBIO, Largo dos Colegiais, 7000, Évora, Portugal \\ ${ }^{3}$ Departmento de Ecologia da Conservação e Entomologia, Universidade de Stellenbosch, \\ Private Bag X1, Matieland 7602, África do Sul
}

\section{Introdução}

As alterações climáticas estão já a alterar a fenologia e distibuição de muitas espécies em todo o mundo (Parmesan 2006) e esperam-se ainda mais mudanças para o século 21 (Araújo et al. in press). As projecções de deslocamento das áreas de distribuição das espécies sob cenários de alterações climáticas colocam um desafio às estratégias actuais de planeamento para a conservação. As regras convencionais para a selecção e gestão de áreas protegidas aplicam-se a situações em que as meta-populações estão em equilíbrio entre extinções e colonizações, mas deixam de ser válidas sob cenários futuros que forçam as espécies a migrar para procurar espaço climático favorável (Araújo 2009b). Numa altura em que as alterações climáticas constituem um ponto alto nas agendas de vários sectores, a revisão das estratégias e prioridades de planeamento para a conservação revela-se igualmente crucial (Araújo 2009b; Hannah et al. 2002; Heller \& Zavaleta 2009; Lawler et al. 2009). Respondendo a uma solicitação do Conselho Europeu, um relatório recente (Araújo 2009a) reviu estratégias de conservação para adaptação às alterações climáticas. As conclusões do relatório contribuíram para discussões sobre a biodiversidade e alterações climáticas entre as Partes da Convenção relativa à Conservação da Vida Selvagem e dos Habitats Naturais da Europa, mas as estratégias revistas são válidas para além das fronteiras europeias. Realçamos aqui três principais estratégias gerais (o relatório contém as referências usadas para os exemplos descritos em cada estratégia).

\footnotetext{
*Send correspondence to: Raquel Amaral Garcia

Departmento de Biodiversidade e Biologia Evolutiva,

Museu Nacional de Ciências Naturais,

Conselho Superior de Investigações Científicas - CSIC,

Calle José Gutiérrez Abascal, 28006, Madrid, Espanha

E-mail: raquel.garcia@mncn.csic.es
}

\section{Gestão Adaptativa em Áreas Protegidas}

Sob cenários de alterações climáticas, as espécies podem encontrar refúgios estacionários (stationary refugia, Araújo 2009b) em áreas protegidas quando a variação climática registada esteja dentro dos seus limites de tolerância ou quando tenham ao seu alcance habitats favoráveis. No entanto, poderá ser necessária a gestão humana de populações e habitats para facilitar a persistência das espécies sob alterações climáticas. Apesar da sua reduzida aplicação especialmente fora dos EUA, a gestão adaptativa é reconhecida cada vez mais como um instrumento crucial para a conservação da biodiversidade face à incerteza que rodeia tanto as projecções das alterações climáticas como as respostas bióticas a essas alterações. A gestão adaptativa implica geralmente o planeamento num horizonte mais alargado, a consideração de ambos os processos locais e globais que ameaçam a biodiversidade, e a monitorizção contínua para reajustar acções (Hannah et al. 2002; Lawler et al. 2009). Encontram-se exemplos nos EUA (Lawler et al. 2009) de estratégias que utilizam uma sequência de medidas para a protecção de populações locais que poderão vir a ser afectadas por um clima em mudança. Enquanto a implementação de medidas gerais deverá beneficar as espécies independentemente das alterações climáticas, um outro grupo de medidas, ligadas de perto às alterações monitorizadas, é desencadeado quando são atingidos os limites de viabilidade das espécies. Na área protegida de Sycan Marsh, por examplo, o habitat da truta Salvelinus confluentus irá provavelmente ser afectado pelas temperaturas mais elevadas que se prevêem para Oregon. Os gestores da área protegida encontram-se actualmente a remover barreiras à dispersão e a restaurar áreas ribeirinhas da rede fluvial para que os peixes possam deslocar-se como resposta às mudanças na temperatura. No entanto, assim que sejam excedidos os limites da espécie relativos à temperatura da água, os gestores terão de voltar a sua atenção a montante, para áreas mais elevadas, onde as condições climáticas poderão ainda permitir a persistência das populações de truta. 


\section{Reforço da Rede de Áreas Protegidas}

Quando as alterações climáticas impeçam as espécies de persistir nas suas localizações originais, aquelas com maiores capacidades de dispersão poderão procurar e colonizar novas áreas que se tornem adequadas à medida que as condições mudem. Para que estes refúgios deslocados (displaced refugia, Araújo 2009b) estejam disponíveis para espécies em migração, poderão ser necessários ajustes nas redes de áreas protegidas para aumentar ou ligar áreas de habitat disponível. Estes ajustes deverão ser guiados pela distribuição esperada dos habitats favoráveis no futuro. Apesar da incerteza inerente às projecções de deslocamentos das áreas de distribuição, existem já esforços para garantir a conservação proactiva de áreas que irão provavelmente tornar-se críticas para a persistência das espécies no futuro. O aumento esperado do nível do mar levou organizações de conservação tanto no Reino Unido como nos EUA a proteger áreas mais afastadas da costa em antecipação ao alagamento de habitats costeiros. Na Flórida, a perspectiva de perder $13 \%$ de espécies e habitats raros devido ao aumento do nível do mar motivou a formulação de um plano de "retirada organizada" para preservar habitats costeiros mais interiores e elevados para as espécies, criar corredores para movimentos bióticos e evitar a construção de mais defesas costeiras.

A um nível mais alargado, encontram-se também em curso iniciativas para promover a conectividade em redes nacionais ou internacionais de áreas protegidas de modo a aumentar a resiliência às alterações climáticas. As modificações planeadas na Rede Nacional Ecológica da Holanda, baseadas em modelos dinâmicos de populações, incluem novas ligações ecológicas e uma maior diversidade de habitats. A necessidade de adaptação às alterações climáticas está a dar novo impulso à conservação transfronteiriça, como o demonstram exemplos de cooperação entre Espanha e Portugal para proteger a biodiversidade ibérica, e entre oito estados alpinos para identificar redes ecológicas prioritárias.

As redes de áreas protegidas podem também ser ajustadas para abarcar uma maior diversidade de habitats, uma abordagem de filtro mais grosseiro com vista a promover a persistência de processos ecológicos e evolutivos que são cruciais para manter e gerar biodiversidade. As redes com maior diversidade estarão provavelmente melhor preparadas para as alterações climáticas (Araújo 2009b). A África do Sul está a ter estas ideias em conta na sua nova Estratégia Nacional de Expansão de Áreas Protegidas. A Estratégia pretende incorporar no planeamento a grande e pequena escalas uma série de regras que se baseiam em características ambientais como indicadores de processos ecológicos e evolutivos. Estes processos podem representar alterações dinâmicas na distribuição de espécies induzidas pelas alterações climáticas e, assim, desempenhar um papel importante na persistência das espécies. Exemplos incluem o uso de dados de ocupação do solo para fornecer indicações sobre a permeabilidade da paisagem à dispersão de espécies e de gradientes topográficos para ajudar na identificação de potenciais refúgios climáticos.

\section{Conservação para Além das Áreas Protegidas}

A dispersão será um mecanismo importante para a adaptação às alterações climáticas (Araújo 2009a), mas as espécies nem sempre poderão persistir ou migrar exclusivamente através de áreas protegidas. Para além dos refúgios estacionários e deslocados, o relatório realça um terceiro tipo de áreas que devem ser alvo das estratégias de adaptação. São necessárias áreas de elevada conectividade (areas of high connectivity, Araújo 2009b) para permitir às espécies atravessar as paisagens à medida que o clima muda, o que realça a importância de estratégias de conservação alargadas à matriz envolvente das áreas formalmente protegidas (Hannah et al. 2002; Heller \& Zavaleta 2009; Opdam \& Wascher 2004). O objectivo destas estratégias é atenuar o uso do solo em áreas alvo da matriz. Dado que estas áreas são em grande parte privadas, tornam-se necessárias medidas de natureza distinta. Requisitos legais, mas também incentivos directos, criação de mercados ou instrumentos educativos podem ser usados para envolver os proprietários numa gestão da matriz "amiga da biodiversidade". O conjunto de instrumentos adequado para cada país ou situação irá depender das motivações dos proprietários para implementar acções de conservação, bem como da possibilidade dos Estados imporem restrições ao uso do solo.

Incentivos positivos tais como as medidas agro-ambientais europeias têm uma longa história na recompensa de agricultores que adoptam práticas amigas da biodiversidade. Ao atenuar as paisagens de produção intensiva (Donald \& Evans 2006), estas medidas podem facilitar a adaptação às alterações climáticas. Na Suíça, por exemplo, os agricultores são elegíveis a pagamentos directos quando estabelecem áreas de compensação ecológica (ACEs) nas suas propriedades. O esquema suíço em Aargau selecciona estas ACEs cuidadosamente de modo a suplementar e ligar ACEs ou áreas protegidas existentes na região. Deste modo, evita a distribuição dispersa dos alvos agro-ambientais que é frequente nestes esquemas e contribui para paisagens mais permeáveis aos movimentos bióticos. A compensação por acções de conservação em terrenos privados pode também tomar a forma de assistência técnica na gestão de habitats ou no controlo de incêndios ou espécies invasoras, serviços de extensão rural e redução de impostos. Nos esquemas voluntários de conservação (stewardship) que existem tanto na província sul africana de Western Cape como no estado australiano de New South Wales, estes benefícios aumentam com níveis mais elevados de empenho dos proprietários na conservação e restrições associadas de uso do solo. Ainda que menos testados, existem ainda exemplos de abordagens de mercado que favorecem práticas amigas da biodiversidade em terrenos privados, tais como esquemas de "biobancos", ecoturismo ou programas de rotulagem ecológica.

Os instrumentos legais mais convencionais oferecem oportunidades para adaptação às alterações climáticas ao imporem restrições ou requisitos para a gestão do uso do solo na matriz. Em Portugal encontra-se em vigor um 
instrumento de planeamento espacial para proteger e controlar o uso de áreas de elevado valor natural que fazem parte de uma rede entitulada "Reserva Ecológica Nacional". Apesar da rede portuguesa não ter sido concebida tendo as alterações climáticas em mente, tem como alvo áreas que podem garantir refúgio climático e proteger processos ecológicos que são cruciais para a persistência das espécies num clima em mudança. As áreas da rede - incluindo, entre outras, zonas declivosas, leitos dos cursos de água e zonas costeiras - foram recentemente integradas no sistema nacional de conservação como "áreas de continuidade". A legislação de Avaliação de Impacte Ambiental pode também ter um papel a desempenhar na adaptação às alterações climáticas, quando são impostas medidas de conservação de habitat prioritário alternativo para compensar os impactes residuais de projectos. Ao localizar estas áreas de compensação, a província de Western Cape, na África do Sul, favorece locais que contribuem para criar ligações espaciais com áreas protegidas e consolidar fragmentos de habitat prioritário. Estes critérios, ainda que não sejam uma resposta directa aos impactes das alterações climáticas, podem promover paisagens mais permeáveis.

Finalmente, os instrumentos de informação e educação desempenham um papel fundamental na adaptação às alterações climáticas independentemente das abordagens seguidas. Um exemplo vem de New South Wales, Austrália, onde foram preparados "perfis de alterações climáticas” para fornecer aos proprietários informação sobre impactes previstos e estratégias sugeridas para cada bacia hidrográfica.

\section{Comentários Finais}

Apesar do número crescente de iniciativas ad-hoc para reduzir os efeitos das alterações climáticas na biodiversidade, estratégias como as que se acabam de descrever aguardam ainda plena integração em políticas e planos de conservação. O conjunto adequado de estratégias irá diferir de local para local, e o seu enfoque terá provavelmente de evoluir do aumento da resiliência dos ecossistemas aos impactes das alterações climáticas a curto prazo, para o encorajamento de uma transição gradual para mudanças inevitáveis a longo prazo (Galatowitsch et al. 2009). Não obstante a incerteza que envolve as projecções climáticas e as respostas bióticas, a protecção da biodiversidade na matriz é uma estratégia que trará benefícios sob qualquer cenário (Hannah et al. 2002). Deverá, por isso, fazer parte de qualquer abordagem de adaptação, em conjunto com mecanismos melhorados de classificação e gestão de redes de áreas protegidas. Face à incerteza existente, a gestão adaptativa oferece aos gestores um instrumento para actuar agora e ajustar as acções à medida que fiquem disponíveis novos resultados.

\section{Agradecimentos}

A R.A.G. é financiada por uma bolsa de doutoramento da FCT Portuguesa (SFRH/BD/65615/2009) e o M.B.A. pelo projecto de investigação EC FP6 ECOCHANGE (GOCE-CT-2007-036866).

\section{Referências}

Araújo MB et al., in press. Effects of climate change on European conservation areas.

Araújo MB, 2009a. Protected areas and climate change in Europe. In A discussion paper prepared for the $29^{\text {th }}$ meeting of the Standing Committee, Convention on the Conservation of European Wildlife and Natural Habitats; Strasbourg; 2009 November 23-26.

Araújo MB, 2009b. Climate change and Spatial Conservation Planning. In Moilanen HPA and Wilson K. (eds). Spatial Conservation Prioritization: quantitative methods and computational tools. Oxford: Oxford University Press. p. $172-184$.

Donald PF \& Evans AD, 2006. Habitat connectivity and matrix restoration: The wider implications of agri-environment schemes. Journal of Applied Ecology, 43:209-218.

Galatowitsch S, Frelich L \& Phillips-Mao L, 2009. Regional climate change adaptation strategies for biodiversity conservation in a midcontinental region of North America. Biological Conservation, 142:2012-2022.

Hannah L, Midgley GF \& Millar D, 2002. Climate changeintegrated conservation strategies. Global Ecology and Biogeography, 11:485-495.

Heller NE \& Zavaleta ES, 2009. Biodiversity management in the face of climate change: A review of 22 years of recommendations. Biological Conservation, 142:14-32.

Lawler JJ et al., 2009. Resource management in a changing and uncertain climate. Frontiers in Ecology and the Environment, 8:35-43.

Opdam P \& Wascher D, 2004. Climate change meets habitat fragmentation: linking landscape and biogeographical scale levels in research and conservation. Biological Conservation, 117:285-297.

Parmesan C, 2006. Ecological and evolutionary responses to recent climate change. Annual Review of Ecology, Evolution and Systematics, 37:637-669.

Recebido: Março 2010

Primeira Decisão: Março 2010 Aceito: Março 2010 